\title{
Blastocystis sp.: waterborne zoonotic organism, a possibility?
}

Li li Lee ${ }^{1}$, Tan Tian Chye ${ }^{1}$, Biraj Man Karmacharya ${ }^{2}$ and Suresh Kumar Govind ${ }^{1 *}$

\begin{abstract}
Background: Blastocystis sp. is a common intestinal parasite found in faecal sample surveys. Several studies have implicated human-to-human, zoonotic and waterborne transmissions by Blastocystis sp. However, there has been no study providing evidence interlinking these three transmissions in a community. We have previously shown a high prevalence of Blastocystis sp. subtype 4 amongst village dwellers in Bahunipati, Nepal, and the present study extends the observation to assess if the same subtype of Blastocystis sp. occurs in animals they rear and rivers they frequent.

Methods: Faecal samples were collected from 65 animals. Four river water samples were collected from two rivers. Faecal samples were examined using in vitro cultivation. Blastocystis sp. from animal faecal and river samples were genotyped using seven subtype-specific sequence tagged site (STS) primer-polymerase chain reaction (PCR).

Results: Blastocystis sp. infected $15.4 \%$ animals with subtype 4 being the predominant genotype (40.0\%). Both rivers were contaminated with Blastocystis sp. subtype 1 and subtype 4, which were also detected in humans living in the same village in our previous study. Blastocystis sp. subtype 4 that was detected in buffalo and pigs was also found in the respective family members that reared these animals.

Conclusions: This unusually high prevalence of Blastocystis subtype 4 found in village dwellers was also found to be pervasive in the animals they reared and the rivers they frequented implying a strong possibility of waterborne zoonosis for Blastocystis sp.
\end{abstract}

Keywords: Blastocystis, Molecular evidence, Nepal, Rural communities, Waterborne zoonosis

\section{Background}

Blastocystis sp. is one of the most commonly found microorganisms infecting the intestine of humans and animals. Its occurrence in drinking water sources has been established through molecular analysis [1,2]. It exists as cyst, vacuolar, granular and amoebic forms and is believed to be transmitted through the faecal-oral route [3]. Several studies on the prevalence and genotyping of Blastocystis sp. in humans, animals or drinking water have been carried out throughout the world, from Asia, Australia, to Europe and America [3]. However, these reports were limited as they focused singly on either human-to-human, zoonotic or waterborne transmission. Thus, no comprehensive study has provided

\footnotetext{
* Correspondence: suresh@um.edu.my

'Department of Parasitology, Faculty of Medicine, University of Malaya, Kuala Lumpur 50603, Malaysia

Full list of author information is available at the end of the article
}

conclusive evidence interlinking these three transmissions in a community.

Human-to-human transmission by Blastocystis hominis subtype 3 has been reported in patients from two longterm health care facilities in Japan [4]. In Malaysia, we demonstrated a high prevalence of Blastocystis sp. in animal handlers [5] and more recently further substantial molecular evidence for zoonotic transmission was provided between animal and animal handlers in the Philippines and Australia [6,7]. In another study, Blastocystis sp. subtype 2 was detected in children and monkeys living within the same area in Kathmandu, Nepal [8]. Moreover, Blastocystis sp. was detected in sewage in Malaysia and Scotland [9] with two studies providing evidence for waterborne transmission by this parasite $[1,2]$.

We have previously highlighted an unusually high prevalence of Blastocystis sp. subtype 4 in two villages,

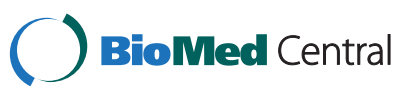


namely Bolde Phediche (76.9\%; 30/39) and Bahunipati (95.8\%; 23/24) in Nepal [10]. During the human faecal sample collection for the previous study in Bahunipati, we had also collected animal faecal sample and water samples. Therefore, we extended the observation in the present study by determining the prevalence of the organism in animal faeces and water sources in Bahunipati, where the prevalence of Blastocystis sp. of subtype 4 was higher in this rural community.

\section{Methods}

\section{Study area and population}

A cross-sectional survey was conducted in a rural village located at Bahunipati in Sindhupalchowk District, Nepal, in November 2009 (Figure 1). This survey was carried out concurrently with human faecal sample collection in the previous study [10]. It is a hilly settlement with agricultural areas and animal farming activities being their livelihood. Faecal samples from 65 animals, including 19 buffaloes, six cows, 29 goats and 11 pigs were collected. These animals were reared by the respective villagers who participated in the previous study [10]. Ethical clearance for the present study was obtained from the Institutional Review Committee of Kathmandu University School of Medical Science/ Dhulikhel Hospital (IRC-KUSMS) with an ethical approval number of 04/10.

\section{Faecal examinations}

Faecal examinations were performed by adding approximately $500 \mathrm{mg}$ of faecal sample into Jones' medium supplemented with $10 \%$ horse serum followed by incubation at $37^{\circ} \mathrm{C}$ and examined daily for the vacuolar form of Blastocystis sp. using light microscopy for the subsequent three days consecutively.

\section{Water sample concentration technique}

A total of four water samples, one litre each, were collected from Indrawati River and Sindukhola River whereby two samples were collected from each river at two sampling points. The water sample collection was carried out concurrently with human faecal sample collection in the previous study [10]. Collected water samples were centrifuged at $1,400 \times g$ for 10 minutes. Water concentrates were kept at $-20^{\circ} \mathrm{C}$ until DNA extraction and further genotyping.

\section{Genotyping by polymerase chain reaction (PCR) using sequenced-tagged site (STS) primers}

The preparation for genomic DNA extraction and genotyping using sequenced-tagged site (STS) primer with seven sets of specific STS primer for genotyping of Blastocystis from subtype 1 to subtype 7 [11] are as described in our previous study [10].

\section{Results and discussion}

Our results showed that 10 animals (15.4\%) were infected with Blastocystis sp. including four buffaloes, a cow, a goat and four pigs (Table 1a). Blastocystis sp. subtype 4 was the predominant subtype detected in animals $(4 / 10$; 40.0\%; Table 2), which were found in a buffalo, a goat and two pigs. In contrast, the remaining six Blastocystis sp. isolates were not type-able with any STS primers used for this study. Therefore, they were categorised as unknown subtypes. All four water samples were contaminated with Blastocystis sp. (Table 1b) and subtype 1 $(100.0 \%)$ was predominantly found followed by subtype 4 (3/4; 75\%) (Table 2).

The present study is timely, as recent The World Health Organization publications on drinking water quality have included Blastocystis sp. as one of the

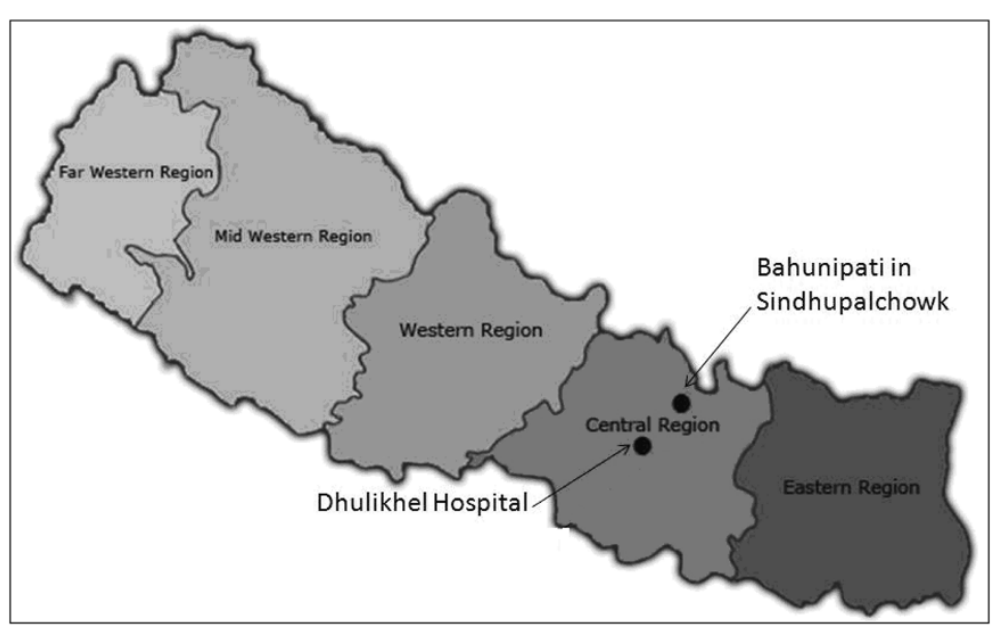

Figure 1 Study area in Bahunipati situated in Central Nepal. 
Table 1 Prevalence of Blastocystis sp. infection amongst animals (a) reared by the villagers in Bahunipati, Nepal and prevalence of Blastocystis sp. contamination in the rivers (b)

\begin{tabular}{llll}
\hline (a) & Animals & $\begin{array}{l}\text { No. of } \\
\text { animal (\%) }\end{array}$ & $\begin{array}{l}\text { No. of animal infected } \\
\text { by Blastocystis sp. (\%) }\end{array}$ \\
\hline Buffalo & $19(29.2)$ & $4(2.1)$ \\
\hline Cow & $6(9.2)$ & $1(1.7)$ \\
\hline Goat & $29(44.6)$ & $1(3.4)$ \\
\hline Pig & $11(16.9)$ & $4(36.4)$ \\
\hline (b) & Total & $65(100.0)$ & $10(15.4)$ \\
\hline & Siver water & $\begin{array}{l}\text { No. of } \\
\text { sample }\end{array}$ & $\begin{array}{l}\text { No. of sample } \\
\text { contaminated with } \\
\text { Blastocystis sp. }\end{array}$ \\
\hline & Indrawati River & $2(50.0)$ & $2(50.0)$ \\
\hline & Total & $4(100.0)$ & $4(100.0)$ \\
\hline
\end{tabular}

pathogens to be considered for waterborne zoonoses $[12,13]$.

In the current study, it is interesting to note that every family from Bahunipati who participated in this survey owned animals, which were reared next to their dwelling. Prevalence of Blastocystis sp. infection in humans in Bahunipati (36.4\%) is by far the highest [10] as compared to two other studies in Nepal, which reported 2.8\% [14] and $25.6 \%$ [8] positive for Blastocystis sp.

Blastocystis sp. subtype 4 has been reported in guinea pig [15], lemur [16], opossum [17], rat [18,19] and woolly monkey [16]. However, our study found Blastocystis sp. subtype 4 in buffalo, goat and pig, which, previously have not been reported for these animals. Nonetheless, it has been reported that Blastocystis sp. subtype 1, 2, 3, 5, and 6 had been isolated from pig [20], but not subtype 4 . From our observation, many of these studies were carried out on animals from the zoo and rarely involved livestock except some from Japan and the Philippines.

In this study, we observed that Blastocystis sp. subtype 4 that was detected in a buffalo and a pig was also found in its respective owner. These animals were reared at close proximity to their owners' houses. In a study carried out in China, molecular-based evidence showed that Blastocystis sp. subtype 5 in pigs was also detectable in

Table 2 Subtype classification of Blastocystis sp. in Bahunipati obtained from animals and rivers

Subtype classification

\begin{tabular}{llllllllll}
\hline & $\mathbf{1}^{\mathbf{a}}$ & $\mathbf{2}$ & $\mathbf{3}$ & $\mathbf{4}^{\mathbf{a}}$ & $\mathbf{5}$ & $\mathbf{6}$ & $\mathbf{7}$ & $\mathbf{U n k n}$ & \\
\hline Animals (10) & 1 & 0 & 0 & 4 & 0 & 0 & 0 & 6 & 1 \\
\hline Waters (4) & 4 & 0 & 0 & 3 & 0 & 0 & 0 & 0 & 3 \\
\hline
\end{tabular}

a Including mixed subtypes $1+4$.

${ }^{\mathrm{b}}$ Blastocystis sp. mixed subtypes infection. the humans who reared those pigs, suggesting that subtype 5 may be transmitted zoonotically [21]. Therefore, in the same light, our finding provides possible molecularbased evidence suggesting zoonotic potential of Blastocystis sp. subtype 4. It has also been reported in our previous study conducted in Malaysia that individuals who work closely with animals do stand at risk of acquiring Blastocystis sp. infection [5]. This finding was further supported by research done for faecal samples collected from animal facilities in the Philippines [6] and in Australia, Belgium and the Netherlands [7].

Our finding concurs with that by Leelayoova and colleagues [1], reporting the presence of Blastocystis sp. subtype 1 in drinking water. From our previous finding [10], it was shown that $37.5 \%$ of individuals in Bahunipati were infected by Blastocystis sp. subtype 1. The same subtype was shown to be present in two rivers that flowed beside the village in Bahunipati. Interestingly, both rivers were also contaminated with Blastocystis sp. subtype 4 while 95.8\% of the communities in Bahunipati were infected by this subtype, which is the predominant subtype found in the community [10]. We observed that a poorly built and maintained septic tank was in close proximity to houses and the river, which could have facilitated seepage of Blastocystis sp. from faeces belonging to humans into the river and thus contaminating drinking water sources. Our previous study also revealed that both the older sister (15 years old) and younger brother (12 years old) in a same family were infected by Blastocystis sp. subtype 4, which could occur through various ways to facilitate human-to-human contamination.

Therefore, the molecular evidence presented in this study suggests that the Indrawati River and the Sindukhola River may be contaminated with faeces containing Blastocystis sp. subtype 4 from humans and Blastocystis sp. subtype 1 and 4 from animals. Since the contaminated rivers are the water sources for this community, drinking water from these rivers may facilitate waterborne contamination of Blastocystis sp. to them. In addition, poor hand hygiene could have facilitated the transmission from animals to humans. It is postulated that Blastocystis sp. subtype 4 that was pervasively found in humans, animals and rivers might be transmitted through human-to-human, zoonotic and waterborne contaminations. All three possible modes of contamination by Blastocystis sp. in Bahunipati, Nepal, are illustrated in Figure 2.

The current study is in agreement with that of Eroglu and Koltas [2], who reported the presence of Blastocystis sp. in infected patients, animals they reared and tap water, which was their source of drinking water. However, only Blastocystis sp. subtypes 1, 2 and 3 were detected in humans and animals, while only subtype 1 was detected in water in that study. Blastocystis sp. 


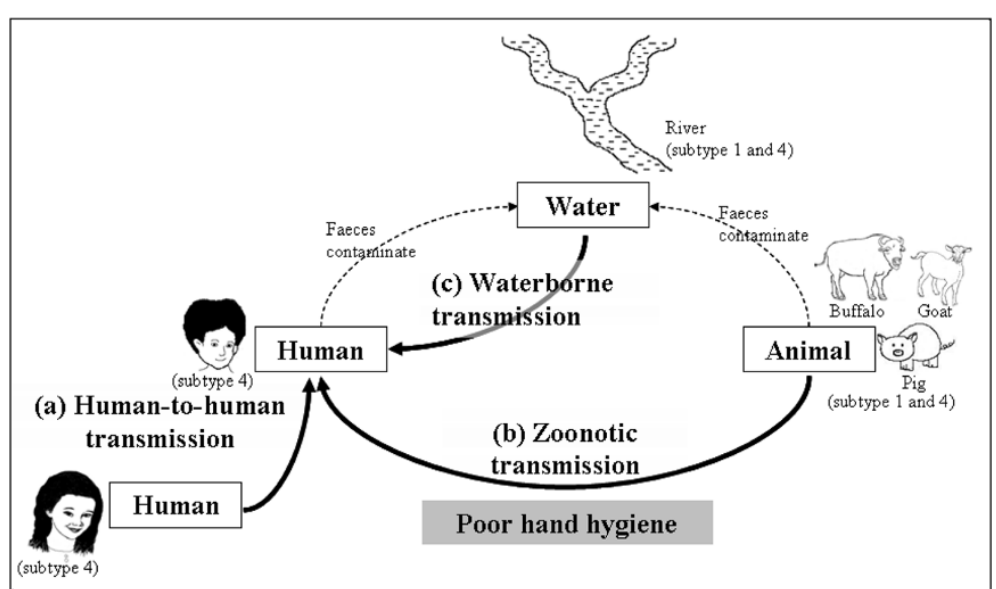

Figure 2 Possible human-to-human, zoonotic and waterborne contaminations by Blastocystis sp. in Bahunipati, Nepal.

subtype 1 has also been reported in drinking water in a study conducted in Northern Thailand [1]. Therefore, the uniqueness of our current study is the detection of subtype 4 in animals and river water samples closely associated with village dwellers with an unusually high prevalence of subtype 4, not commonly seen in human populations. Even in studies where Blastocystis sp. subtype 4 was reported as the predominant subtype, it was found in patients $[22,23]$ and not in rural communities [10].

\section{Conclusions}

To the best of our knowledge, this is the first study to comprehensively provide molecular evidence supporting waterborne zoonotic transmission of Blastocystis sp. in a rural community. Specially, our data suggests the presence of waterborne and zoonotic transmissions of Blastocystis sp. subtype 4 . We suggest that screening for Blastocystis sp. contamination needs to be performed as part of water quality assessments. Public education and proper management of livestock contamination may help reduce the incidence of Blastocystis sp. transmission in such communities.

\section{Competing interests}

The authors declare that they have no competing interests.

\section{Authors' contributions}

LIL participated in the design of the study, performed all sample collection, examination of the samples, analysed the results and wrote the manuscript. TTC participated in the design of the study and revised the manuscript. BMK coordinated the research in Nepal. SKG conceived the study, participated in the design of the study and revised the manuscript. All authors read and approved the final version of the manuscript.

\section{Acknowledgements}

The authors thank the staffs at the Department of Parasitology, Department of Microbiology and Department of Community Programmes in Dhulikhel Hospital Kathmandu University Hospital, participants and officers from Bahunipati Health Centre for their commitment. This study was supported by UM.C/625/1/HIR/031, a research grant awarded by University of Malaya.

\section{Author details}

Department of Parasitology, Faculty of Medicine, University of Malaya, Kuala Lumpur 50603, Malaysia. ${ }^{2}$ Department of Community Programmes, Dhulikhel Hospital Kathmandu University Hospital, Dhulikhel Kavre, GPO Box 11008,

Kathmandu, Nepal.

Received: 24 January 2012 Accepted: 15 April 2012

Published: 28 June 2012

\section{References}

1. Leelayoova S, Siripattanapipong S, Thathaisong U, Naaglor T, Taamasri P, Piyaraj P, Mungthin M: Drinking water: a possible source of Blastocystis spp. subtype 1 infection in schoolchildren of a rural community in Central Thailand. AmJTrop Med Hyg 2008, 79:401-406.

2. Eroglu F, Koltas IS: Evaluation of the transmission mode of Blastocystis hominis by using PCR method. Parasitol Res 2010, 107:841-845.

3. Tan KSW: New insights on classification, identification, and clinical relevance of Blastocystis spp. Clin Microbiol Rev 2008, 21:639-665.

4. Yoshikawa H, Abe N, Iwasawa M, Kitano S, Nagano I: Genomic analysis of Blastocystis hominis strains isolated from two long-term health care facilities. J Clin Microbiol 2000, 38:1324-1330

5. Rajah-Salim H, Suresh KG, Vellayan S, Mak JW, Khairul AA, Init I, Vennila GD, Saminathan R, Ramakrishnan K: Blastocystis in animal handlers. Parasitol Res 1999, 85:1032-1033

6. Rivera WL: Phylogenetic analysis of Blastocystis isolates from animal and human hosts in the Philippines. Vet Parasitol 2008, 156:178-182. doi:10.1016/j.vetpar.2008.06.001

7. Parkar U, Traub RJ, Vitali S, Elliot A, Levecke B, Robertson I, Geurden T, Steele J, Drake B, Thompson RC: Molecular characterization of Blastocystis isolates from zoo animals and their animal-keepers. Vet Parasitol 2010, 169:8-17.

8. Yoshikawa H, Wu Z, Pandey K, Pandey BD, Sherchand JB, Yanagi T, Kanbara H: Molecular characterization of Blastocystis isolates from children and rhesus monkeys in Kathmandu, Nepal. Vet Parasito/ 2009, 160:295-300.

9. Suresh KG, Smith HV, Tan TC: Viable Blastocystis hominis cysts in Scottish and Malaysian sewage samples. Appl Environ Microbiol 2005, 71:5619-5620

10. Lee IL, Tan TC, Tan PC, Nanthiney DR, Biraj MK, Surendra KM, Suresh KG: Predominance of Blastocystis sp. subtype 4 in rural communities, Nepal. Parasitol Res 2012, 110:1553-1562.

11. Yoshikawa H, Wu Z, Kimata I, Iseki M, Ali IKMD: Polymerase chain reactionbased genotype classification among human Blastocystis hominis populations isolated from different countries. Parasitol Res 2004, 94:22-29.

12. Suresh K, Smith HV: Tropical organisms in Asia/Africa/South America. In Waterborne zoonoses: identification, causes, and control. Edited by Cotruvo JA Dufour A, Rees G, Bartram J, Carr R, Cliver DO, Craun GF, Fayer R, Gannon VPJ. London: IWA Publishing: 2004:100-121.

13. World Health Organization: Microbial fact sheets. In World Health Organization Guidelines for Drinking-Water Quality (WHO GDWQ). 4th edition. Malta: Gutenberg; 2011:271-273. 
14. Sherchand JB, Larsson S, Shrestha MP: Intestinal parasites in children and adults with and without abdominal discomfort from the Kathmandu area of Nepal. Trop Gastroenterol 1996, 17:15-22.

15. Leipe DD, Tong ST, Goggin CL, Slemenda SB, Pieniazek NJ, Sogin ML: 16 S-like DNA sequences from Developayella elegans, Labyrinthuloides haliotidis, and Proteromonas lacertae confirm that the stramenopiles are a primarily heterotrophic group. Eur J Protistology 1996, 32:449-458.

16. Stensvold CR, Lewis HC, Hammerum AM, Porsbo LJ, Nielsen SS, Olsen KE, Arendrup MC, Nielsen HV, Molbak K: Blastocystis: unravelling potential risk factors and clinical significance of a common but neglected parasite. Epidemiol Infect 2009, 137:1655-1663.

17. Parkar U, Traub RJ, Kumar S, Mungthin M, Vitali S, Leelayoova S, Morris $K$, Thompson RC: Direct characterization of Blastocystis from faeces by PCR and evidence of zoonotic potential. Parasitology 2007, 134:359-367.

18. Noël C, Peyronnet C, Gerbod D, Edgcomb VP, Delgado-Viscogliosi P, Sogin ML, Capron M, Viscogliosi E, Zenner L: Phylogenetic analysis of Blastocystis isolates from different hosts based on the comparison of small-subunit rRNA gene sequences. Mol Biochem Parasitol 2003, 126:119-123.

19. Noël C, Dufernez F, Gerbod D, Edgcomb VP, Delgado-Viscogliosi P, Ho LC, Singh M, Wintjens R, Sogin ML, Capron M, Pierce R, Zenner L, Viscogliosi E: Molecular phylogenies of Blastocystis isolates from different hosts implications for genetic diversity identification of species, and zoonosis. J Clin Microbiol 2005, 43:348-355.

20. Yoshikawa $\mathrm{H}$, Abe N, Wu Z: PCR-based identification of zoonotic isolates of Blastocystis from mammals and birds. Microbiology 2004, 150:1147-1151.

21. Yan Y, Su S, Ye J, Lai X, Lai R: Blastocystis sp. subtype 5: a possibly zoonotic genotype. Parasitol Res 2007, 101:1527-1532.

22. Domínguez-Márquez MV, Guna R, Muñoz C, Gómez-Muñoz MT, Borrás R: High prevalence of subtype 4 among isolates of Blastocystis hominis from symptomatic patients of a health district of Valencia (Spain). Parasitol Res 2009, 105:949-955.

23. Stensvold CR, Christiansen DB, Olsen KE, Nielsen HV: Blastocystis sp. subtype 4 is common in Danish Blastocystis-positive patients presenting with acute diarrhea. AmJTrop Med Hyg 2011, 84:883-885.

doi:10.1186/1756-3305-5-130

Cite this article as: Lee et al:: Blastocystis sp.: waterborne zoonotic organism, a possibility?. Parasites \& Vectors 2012 5:130.

\section{Submit your next manuscript to BioMed Central and take full advantage of:}

- Convenient online submission

- Thorough peer review

- No space constraints or color figure charges

- Immediate publication on acceptance

- Inclusion in PubMed, CAS, Scopus and Google Scholar

- Research which is freely available for redistribution 